DOI: https://doi.org/10.36910/6775-2524-0560-2021-44-03

УДК 621.317

Казарова Інна Олександрівна, к.т.н., доцент кафедра теплофізики, молекулярної фізики та

енергоефективності

https://orcid.org/0000-0002-3178-0826

Харківський національний університет імені В. Н. Каразіна

\title{
ПОБУДОВА КОМПЛЕКСНОЇ МЕТОДИКИ ОЦІНКИ ЕФЕКТИВНОСТІ АВТОМАТИЗАЦЇ̈ СИСТЕМ ОПАЛЕННЯ, ВЕНТИЛЯЦІЯ ТА КОНДИЦІЮВАННЯ ПОВІТРЯ
}

\begin{abstract}
Казарова І. О. Побудова комплексної методики оцінки ефективності автоматизації систем опалення, вентиляція та кондиціювання повітря. Розглянуто сучасні методи збільшення ефективності енергопостачання житлових комплексів за рахунок оптимізації систем опалення, вентиляції та кондиціювання повітря. Проведено комплексний аналіз вимог до систем автоматизованого клімат-контролю житлових та робочих приміщень. Запропонована схема контролю параметрів системи опалення, вентиляції та кондиціювання повітря, що включає у себе аналіз температури повітря, а також рівня вологості і забруднення повітря. Розроблено математичну модель регулювання температури повітря у приміщенні, яка базується на визначенні ключових параметрів термодинамічної системи відповідно ідеального циклу Карно. Вказано підходи адаптації моделі для вирішення актуальних завдань та оптимізації систем енергопостачання через визначення екстремумів цільових функцій системи опалення, вентиляції та кондиціювання повітря.
\end{abstract}

Ключові слова:система енергопостачання,системи опалення, вентиляції та кондиціювання повітря,енергоефективність, термодинамічна система, математична модель, цикл Карно, цільові функції.

Казарова И. А. Построение комплексной методики оценки эффективности автоматизации систем отопления, вентиляция и кондиционирование воздуха. Рассмотрены современные методы увеличения эффективности энергоснабжения жилых комплексов за счет оптимизации систем отопления, вентиляции и кондиционирования воздуха. Проведен комплексный анализ требований к системам автоматизированного климат-контроля жилых и рабочих помещений. Предложенная схема контроля параметров системы отопления, вентиляции и кондиционирования воздуха, которая включает в себя анализ температуры, а также уровня влажности и загрязнения воздуха. Разработана математическая модель регулирования температуры воздуха в помещении, основанная на определении ключевых параметров термодинамической системы в соответствии с идеальным циклом Карно. Указаны подходы по адаптации данной модели для решения актуальных задач и оптимизации систем энергоснабжения через определение экстремумов целевых функций системы отопления, вентиляции и кондиционирования воздуха.

Ключевые слова: система энергоснабжения, системы отопления, вентиляции и кондиционирования воздуха, энергоэффективность, термодинамическая система, математическая модель, цикл Карно, целевые функции.

Kazarova Inna. Development of comprehensive methodology for estimation of the heating, ventilation and air conditioning systems automation effectiveness. Modern methods of increasing the efficiency of energy supply of residential complexes by optimizing heating, ventilation and air conditioning systems are considered. A comprehensive analysis of the requirements for automated climate control systems for apartments and workplace has been carried out. There were proposed scheme for controlling the parameters of the heating, ventilation and air conditioning system, which includes the analysis of temperature, as well as the level of humidity and air pollution. A mathematical model has been developed for regulating the air temperature in the room, based on the determination of the key parameters of the thermodynamic system in accordance with the ideal Carnot cycle. Approaches for adapting this model for solving urgent problems and optimizing power supply systems through determining the extrema of the target functions of the heating, ventilation and air conditioning system are indicated.

Key words: power supply system, heating, ventilation and air conditioning systems, energy efficiency, thermodynamic system, mathematical model, Carnot cycle, objective functions.

Вступ. Масове впровадження комунальних послуг по енергопостачанню у рамках житлових та виробничих сервісів на сьогоднішній день становить основну частку навантаження на системи енергозабезпечення [1]. Відповідно до цього у рамках вирішення задачі оптимізації енергокомплексу окрім досліджень по моделюванню та модифікації системи енергозабезпечення [2-4] необхідно також визначити фактори, що впливають на ефективність систем опалення, вентиляції та кондиціювання повітря (Heating, Ventilation and Air Conditioning, HVAC) 3 метою їх подальшої модифікації. На сьогоднішній день HVAC розглядається як сукупність інженерних систем, що застосовуються для налаштування параметрів мікроклімату в залежності від вимог по перебуванню людей,проведенню технологічних процесів та надійному зберіганню товарів і речовин. Побудова математичної моделі та оптимізація відповідно ключових параметрів моделі схеми налаштування HVAC надасть можливість прогнозувати і контролювати рівень енергоспоживання, що разом з заходами по оптимізації систем енергозабезпечення, дозволить збільшити якість та зменшити собівартість комунальних послуг (рис. 1). 


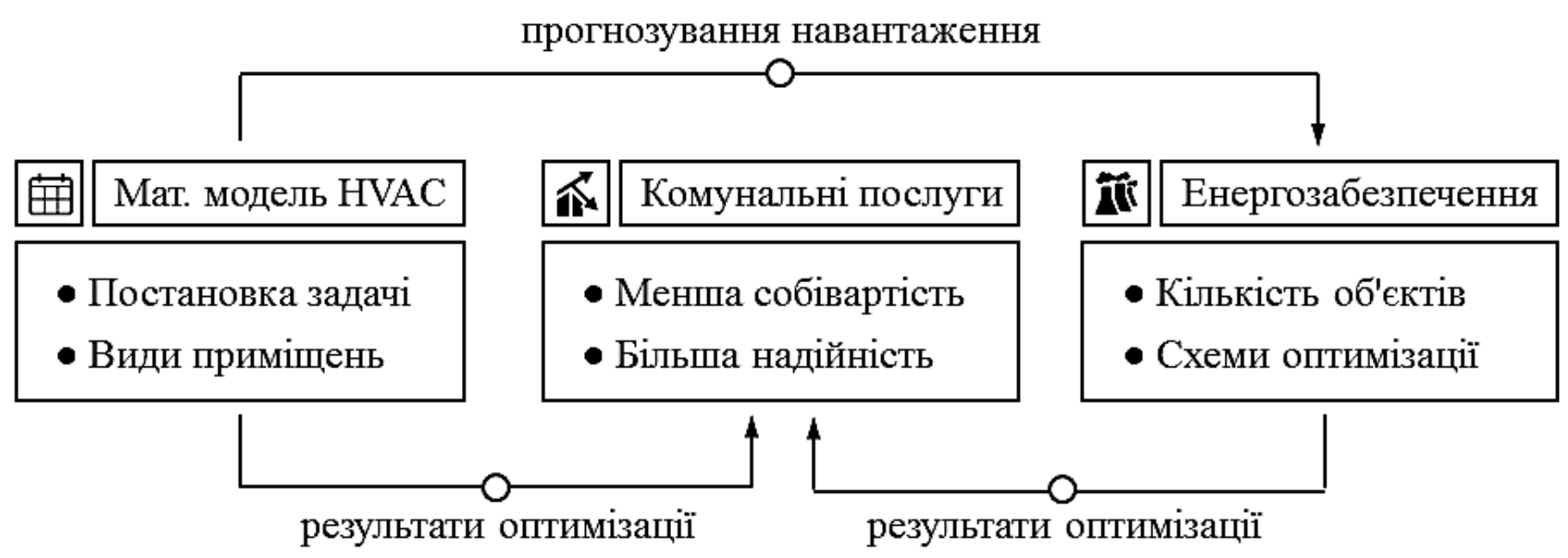

Рис. 1. Комплексна методика оптимізації системи енергозабезпечення.

Аналіз сучасних досліджень і публікацій присвячених проблемам оптимізації систем HVAC показав, що на рівні постановки задачі доцільно класифікувати споживачів комунальних послуг по енергопостачанню відповідно до типів приміщень. Таким чином було виділено наступні базові групи: - $\quad$ житлові комплекси: приватні будинки, багатоквартирна забудова, гуртожитки, тощо [5, 6];

- $\quad$ м

- $\quad$ виробничі приміщення: цехи, фабрики, склади, тощо[9, 10];

- $\quad$ об'єкти громадського доступу: навчальні заклади, транспортні вузли, торгівельно-розважальні комплекси, тощо [11, 12].

Зазначена класифікація надає можливість визначити обмеження згідно котрих розраховуються екстремуми цільових функцій (мінімум показника навантаження на систему енергоспоживання та мінімуми показників відхилень від стабільного рівня заданих параметрів мікроклімату). При цьому слід зазначити стійке зростання вимог до систем HVAC, що пов'язано з посиленням норм з техніки безпеки, організації праці, утримання тварин, умов зберігання продукції, підтримки режиму «чистого приміщення», тощо. Це вирішується як через розширення інструментарію функціональних компонент систем HVAC так і завдяки вдосконаленню модулів автоматизованого контролю зазначених систем[13-15]. Наступна система класифікації, що має бути розглянута при оптимізації клімат-контролю базується на геометричному розмірі приміщень, етажності будинків та налагодження загальної для будинки системи пасивної вентиляції через витяжні шахти [16-18]. Наявність зазначених факторів вказує на необхідність проведення моделювання їх взаємного впливу, у той час як сучасні математичні моделі базуються на аналізі окремих систем HVAC[18-21], що розглядається як невирішена частина загального дослідження.

Таким чином, метою дослідження є розробка комплексної методики оптимізації систем HVAC відповідно задачі зменшення та стабілізації рівня навантаження на систему енергопостачання шляхом побудови математичної моделі та розрахунку на її основі цільових функцій ефективностіHVAC.

\section{1. Постановка задачі налаштування та оптимізація системНVAC}

Для побудови математичної моделі систем HVAC необхідно провести формалізацію ключових параметрів через введення відповідних функцій та їх аргументів. Сучасні системи контролю мікроклімату визначають і регулюють температуру повітря у приміщенні (In-Doors Temperature, ID)відповідно температури поза приміщенням (Out-Doors Temperature, OD), рівень вологості повітря як функцію від температури, швидкість потоку повітря і рівень забруднення повітря. Представимо наступний набір показників сенсорної мережі і модулю керування системи HVAC:

- $\quad \mathrm{T}_{\mathrm{ID}}(\mathrm{t}) \mathrm{i} \mathrm{T}_{\mathrm{OD}}(\mathrm{t})$ як поточний рівень температуриповітря у приміщенні і поза приміщенням, відповідно, де аргумент $\mathrm{t}$ відповідає часу;

- $\quad \mathrm{T}_{\mathrm{ID}}^{0} \mathrm{i} \Delta \mathrm{T}_{\mathrm{ID}}^{+}$як задане значення температури повітря у приміщенні та максимально допустиме відхилення від нього, відповідно; $\left\{\mathrm{T}_{\mathrm{ID}}^{0} ; \Delta \mathrm{T}_{\mathrm{ID}}^{+}\right\}$

- $\mathrm{H}_{\mathrm{ID}}\left(\mathrm{T}_{\mathrm{ID}}(\mathrm{t})\right)$ i $\mathrm{H}_{\mathrm{OD}}\left(\mathrm{T}_{\mathrm{OD}}(\mathrm{t})\right)$ як поточний рівень вологості повітря у приміщенні $\mathrm{i}$ поза приміщенням, відповідно, в залежності від температури; 
- $\quad \mathrm{H}_{\mathrm{ID}}^{0} \mathrm{i} \Delta \mathrm{H}_{\mathrm{ID}}^{+}$як задане користувачем сервісу значення рівня вологості повітря у приміщенні та максимально допустиме відхилення від нього, відповідно;

- $\quad \mathrm{v}_{\mathrm{ID}}(\mathrm{t})$ i $\mathrm{v}_{\mathrm{OD}}(\mathrm{t})$ як поточна швидкість потоку повітря у приміщенні і поза приміщенням, відповідно, де аргумент $\mathrm{t}$ відповідає часу;

- $\quad \mathrm{v}_{\mathrm{ID}}^{0} \mathrm{i} \Delta \mathrm{v}_{\mathrm{ID}}^{+}$як задане користувачем сервісу значення швидкості потоку повітря у приміщенні та максимально допустиме відхилення від нього, відповідно;

- $\quad \Phi_{\mathrm{O}_{2}} \mathrm{i} \Phi_{\mathrm{CO} 2}$ як рівень кисню та вуглекислого газу у повітрі приміщення, відповідно;

- $\quad \Phi_{\mathrm{O} 2}^{0} \mathrm{i} \Delta \Phi_{\mathrm{O} 2}^{+}$як задане користувачем сервісу значення рівня кисню у повітрі приміщення та максимально допустиме відхилення від нього, відповідно;

- $\quad \Phi_{\mathrm{CO} 2}^{0} \mathrm{i} \Delta \Phi_{\mathrm{CO} 2}^{+}$як задане 3 користувачем сервісу значення рівня вуглекислого газу у повітрі приміщення та максимально допустиме відхилення від нього, відповідно;

- $\quad \Phi_{\mathrm{n}}$ як рівень шкідливих домішок у повітрі приміщення, де $\mathrm{n} \in[1 ; \mathrm{N}] \epsilon$ кількістю домішок, що визначаються системою HVAC;

- $\Phi_{\mathrm{n}}^{0}$ і $\Delta \Phi_{\mathrm{n}}^{+}$як задане користувачем сервісу значення рівня шкідливих домішок у повітрі приміщення та максимально допустиме відхилення від нього, відповідно.

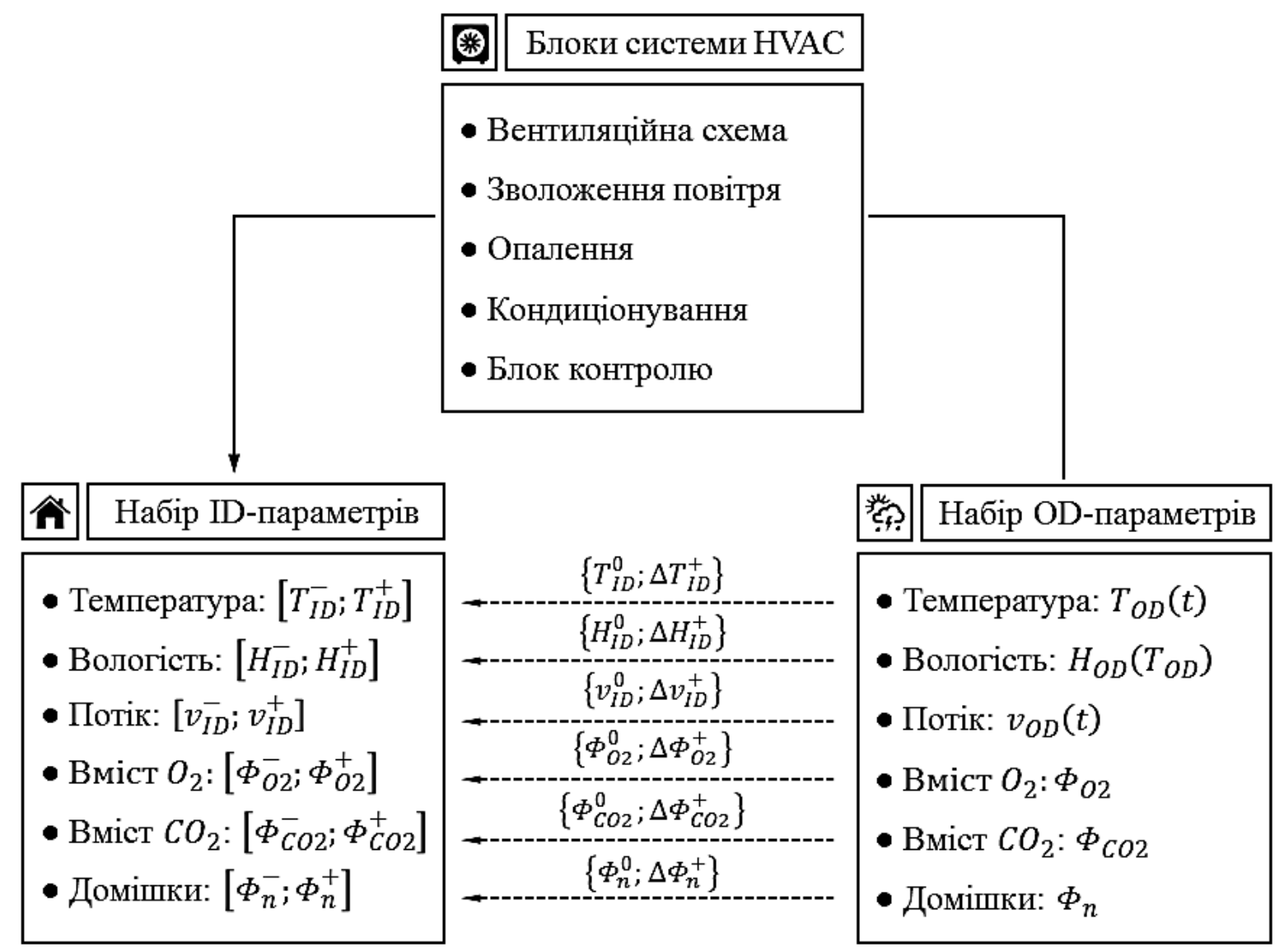

Рис. 2. Базова схему контролю параметрів мікроклімату системою HVAC.

Таким чином, для кожного з показників сенсорної системи відповідно до значень заданих на рівні контрольного блоку можна визначити допустимі межі відхилення показників температури $\left[\mathrm{T}_{\mathrm{ID}}^{-} ; \mathrm{T}_{\mathrm{ID}}^{+}\right]$, вологості[$\left[\mathrm{H}_{\mathrm{ID}}^{-} ; \mathrm{H}_{\mathrm{ID}}^{+}\right]$, швидкості потоку $\left[\mathrm{v}_{\mathrm{ID}}^{-} ; \mathrm{V}_{\mathrm{ID}}^{+}\right]$, рівня кисню[$\left.\Phi_{\mathrm{O} 2}^{-} ; \Phi_{\mathrm{O} 2}^{+}\right]$, рівня вуглекислого газу $\left[\Phi_{\mathrm{CO} 2}^{-} ; \Phi_{\mathrm{CO} 2}^{+}\right]$та домішок $\left\{\left[\Phi_{1}^{-} ; \Phi_{1}^{+}\right],\left[\Phi_{2}^{-} ; \Phi_{2}^{+}\right], \ldots,\left[\Phi_{\mathrm{n}}^{-} ; \Phi_{\mathrm{n}}^{+}\right], \ldots,\left[\Phi_{\mathrm{N}}^{-} ; \Phi_{\mathrm{N}}^{+}\right]\right\}$і налаштувати системи контролю відповідно до цього (рис. 2):

$$
\left\{\begin{array}{l}
\mathrm{T}_{\mathrm{ID}}^{-}=\mathrm{T}_{\mathrm{ID}}^{0}-\Delta \mathrm{T}_{\mathrm{ID}}^{+} \\
\mathrm{T}_{\mathrm{ID}}^{+}=\mathrm{T}_{\mathrm{ID}}^{0}+\Delta \mathrm{T}_{\mathrm{ID}}^{+}
\end{array}, \quad\left\{\begin{array}{l}
\mathrm{H}_{\mathrm{ID}}^{-}=\mathrm{H}_{\mathrm{ID}}^{0}-\Delta \mathrm{H}_{\mathrm{ID}}^{+} \\
\mathrm{H}_{\mathrm{ID}}^{+}=\mathrm{H}_{\mathrm{ID}}^{0}+\Delta \mathrm{H}_{\mathrm{ID}}^{+}
\end{array}, \quad\left\{\begin{array}{l}
\mathrm{v}_{\mathrm{ID}}^{-}=\mathrm{v}_{\mathrm{ID}}^{0}-\Delta \mathrm{v}_{\mathrm{ID}}^{+} \\
\mathrm{v}_{\mathrm{ID}}^{+}=\mathrm{v}_{\mathrm{ID}}^{0}+\Delta \mathrm{v}_{\mathrm{ID}}^{+}
\end{array},\right.\right.\right.
$$




$$
\begin{aligned}
& \left\{\begin{array}{l}
\Phi_{\mathrm{O} 2}^{-}=\Phi_{\mathrm{O} 2}^{0}-\Delta \Phi_{\mathrm{O} 2}^{+} \\
\Phi_{\mathrm{O} 2}^{+}=\Phi_{\mathrm{O} 2}^{0}+\Delta \Phi_{\mathrm{O} 2}^{+}
\end{array}, \quad\left\{\begin{array}{l}
\Phi_{\mathrm{CO} 2}^{-}=\Phi_{\mathrm{CO} 2}^{0}-\Delta \Phi_{\mathrm{CO} 2}^{+} \\
\Phi_{\mathrm{C} 02}^{+}=\Phi_{\mathrm{CO} 2}^{0}+\Delta \Phi_{\mathrm{C} 2}^{+}
\end{array},\right.\right. \\
& \left\{\begin{array}{l}
\Phi_{\mathrm{n}}^{-}=\Phi_{\mathrm{n}}^{0}-\Delta \Phi_{\mathrm{n}}^{+} \\
\Phi_{\mathrm{n}}^{+}=\Phi_{\mathrm{n}}^{0}+\Delta \Phi_{\mathrm{n}}^{+}
\end{array} \text {для } \forall \mathrm{n} \in[1 ; \mathrm{N}]\right.
\end{aligned}
$$

Для побудови математичного апарату необхідно визначити енергоефективність на основі теплового навантаження відповідно ідеальної математичної моделі процесів опалення і кондиціювання, що мають бути доповнені розрахунками рівня вологості та хімічного складу повітря.

\section{2. Побудова математичної моделі функціонування систем HVAC}

Базова математична модель підтримки температурного режиму повітря у приміщенні у заданих межах шляхом нагріву зовнішнього повітря протягом фіксованого проміжку часу $t \in$ $\left[\mathrm{t}^{-} ; \mathrm{t}^{+}\right]$базується на ідеальному циклі Карно через аналіз джерел нагріву (побутові електроприлади, офісна техніка, тощо) та їх розташування (рис. 3). Характерно, що у даному випадку не враховується енергоспоживання при транспортуванні і розподілі теплоносія. Також, слід зазначити, що у рамках вказаної моделі площа теплообміну розглядається як необмежена. Для включення у математичну модель джерел тепла (Heat Source, HS) введемо набір функцій температур $\left\{\mathrm{T}_{\mathrm{k}}^{\mathrm{HS}}(\mathrm{t})\right\}$, деk $\in[1 ; \mathrm{K}]-$ кількість відповідних джерел. Для оптимізації роботи систем HVAC необхідно визначити набір пар різниці температури $\mathrm{HS} 3$ температурою повітря у приміщенні та поза приміщенням: $\left\{\Delta \mathrm{T}_{\mathrm{k}}^{\mathrm{ID}}(\mathrm{t}), \Delta \mathrm{T}_{\mathrm{k}}^{\mathrm{OD}}(\mathrm{t})\right\}$, що розраховуються як:

$$
\left\{\begin{array}{c}
\Delta \mathrm{T}_{\mathrm{k}}^{\mathrm{ID}}(\mathrm{t})=\mathrm{T}_{\mathrm{k}}^{\mathrm{HS}}(\mathrm{t})-\mathrm{T}_{\mathrm{ID}}(\mathrm{t}) \\
\Delta \mathrm{T}_{\mathrm{k}}^{\mathrm{OD}}(\mathrm{t})=\mathrm{T}_{\mathrm{k}}^{\mathrm{HS}}(\mathrm{t})-\mathrm{T}_{\mathrm{OD}}(\mathrm{t})
\end{array}\right.
$$

на основі яких визначається необхідний рівень нагріву чи кондиціювання приміщення. Математична модель, що базується на ідеальному циклі Карно базується на показниках поглинання теплового навантаження $\mathrm{q}_{\mathrm{k}}$ для заданої температури відповідно значення потужності електроенергії $\mathrm{W}_{\mathrm{k}}$, що споживається.

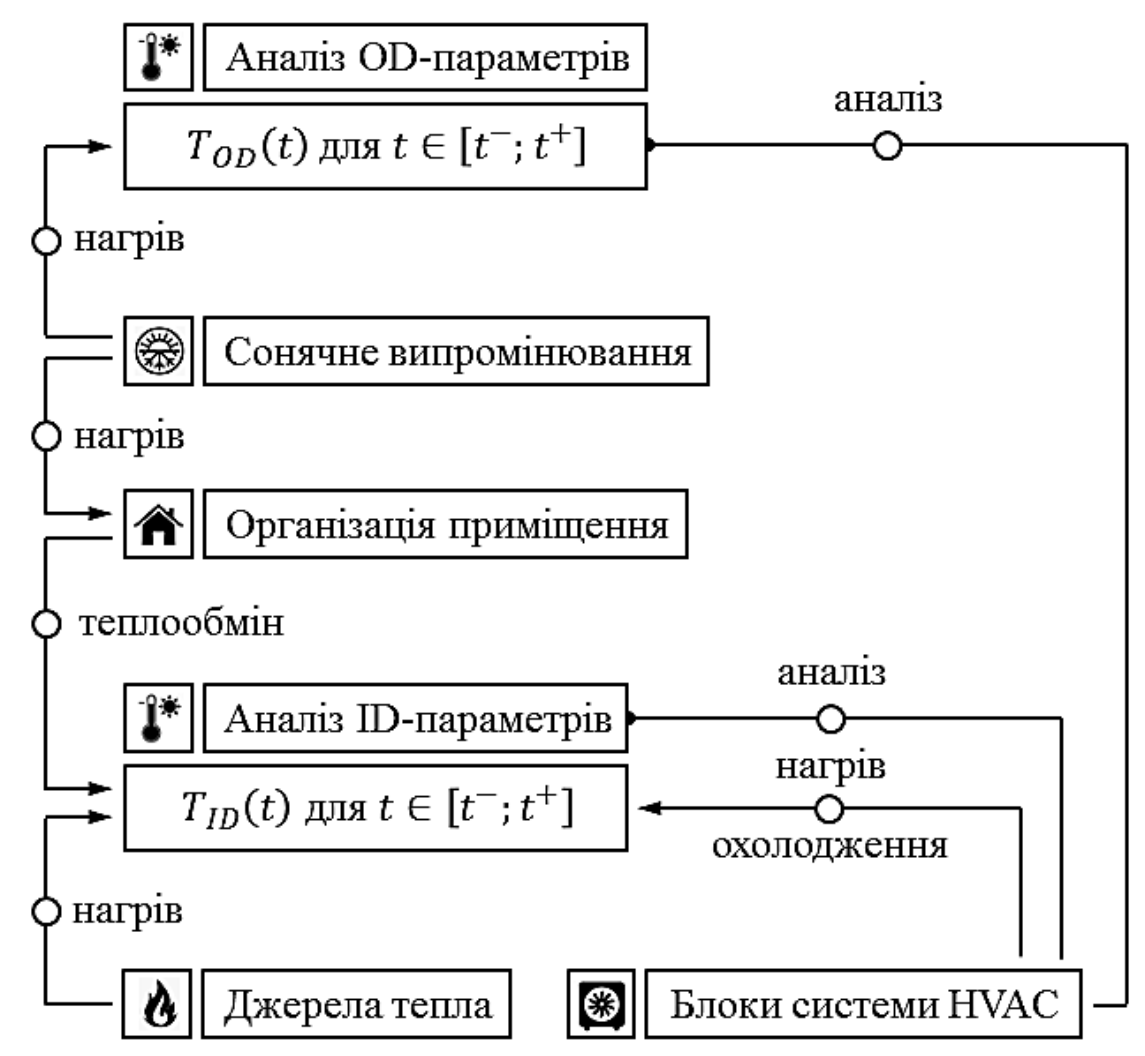

Рис. 3. Модель охолодження на нагріву повітря у приміщенні. 
Повний об’єм теплового навантаження, що споживається проміжку часу $\mathrm{t} \in\left[\mathrm{t}^{-} ; \mathrm{t}^{+}\right]$, розраховується через функцію sign():

$$
\begin{aligned}
& \mathrm{q}_{\Sigma}= \int_{\mathrm{t}=\mathrm{t}^{-}}^{\mathrm{t}^{+}}\left(\sum_{\mathrm{k}=1}^{\mathrm{K}}\left(\mathrm{q}_{\mathrm{k}} \cdot \operatorname{sign}\left(\mathrm{T}_{\mathrm{k}}^{\mathrm{HS}}(\mathrm{t}), \mathrm{T}_{\mathrm{ID}}(\mathrm{t})\right)\right)\right) \mathrm{dt}, \\
& \text { де } \operatorname{sign}\left(\mathrm{T}_{\mathrm{k}}^{\mathrm{HS}}(\mathrm{t}), \mathrm{T}_{\mathrm{ID}}(\mathrm{t})\right)=\left\{\begin{array}{l}
1 \text { при } \Delta \mathrm{T}_{\mathrm{k}}^{\mathrm{ID}}(\mathrm{t})<0 \\
0 \text { при } \Delta \mathrm{T}_{\mathrm{k}}^{\mathrm{ID}}(\mathrm{t}) \geq 0
\end{array} .\right.
\end{aligned}
$$

При цьому повна потужність, що споживається системами HVAC також може бути розрахована через функцію $\operatorname{sign}()$ при розрахунку показників корисної дії (ККД), як набору $\left\{\eta_{\mathrm{k}}\right\}$ :

$$
\mathrm{W}_{\Sigma}=\int_{\mathrm{t}=\mathrm{t}^{-}}^{\mathrm{t}^{+}}\left(\sum_{\mathrm{k}=1}^{\mathrm{K}}\left(\frac{\mathrm{q}_{\mathrm{k}} \cdot \operatorname{sign}\left(\mathrm{T}_{\mathrm{k}}^{\mathrm{HS}}(\mathrm{t}), \mathrm{T}_{\mathrm{ID}}(\mathrm{t})\right)}{\eta_{\mathrm{k}}}\right)\right) \mathrm{dt}, \text { де } \eta_{\mathrm{k}}=\int_{\mathrm{t}=\mathrm{t}^{-}}^{\mathrm{t}^{+}} \frac{\mathrm{T}_{\mathrm{ID}}(\mathrm{t})}{\Delta \mathrm{T}_{\mathrm{k}}^{\mathrm{ID}}(\mathrm{t})} \mathrm{dt} \text {. (7) }
$$

Вирішення задачі оптимізації функціонування загального комплексу систем HVAC полягає у обчисленні екстремуму цільової функції ефективності, тобто максимуму ККД, що розраховується як співвідношення повного об'єму теплового навантаження до повної потужності. Якщо у зазначене рівняння підставити значення $\mathrm{W}_{\Sigma}(7)$, можна отримати:

$$
\eta_{+}=\frac{\int_{t=t^{-}}^{t^{+}}\left(\sum_{k=1}^{K} q_{k}\right) d t}{\int_{t=t^{-}}^{t^{+}}\left(\sum_{k=1}^{K}\left(\frac{\mathrm{q}_{k} \cdot \operatorname{sign}\left(\mathrm{T}_{\mathrm{k}}^{\mathrm{HS}}(\mathrm{t}), \mathrm{T}_{\mathrm{ID}}(\mathrm{t})\right)}{\eta_{\mathrm{k}}}\right)\right) \mathrm{dt}} .
$$

Відповідно постановки задачі оптимізації, зазначений підхід може бути використано для аналізу реальних систем HVAC шляхом (i) врахування взаємного впливу процесів зміни температури та вологості повітря, (ii) адаптації моделі ідеального циклу Карно до системи охолодження, (iii)визначення особливостей розподілу енергії та (iv)врахування обмежень по передачі тепла.

Висновки. В результаті проведеного дослідження було розглянуто збільшення ефективності систем енергопостачання шляхом оптимізації загального комплексу систем опалення, вентиляція та кондиціювання повітря. Аналіз вимог до систем автоматизованого клімат-контролю житлових та робочих приміщень вказав на необхідність комплексного підходу при оптимізації системи енергозабезпечення. В результаті була запропонована схема контролю параметрів системи опалення, вентиляції та кондиціювання повітря, що включає у себе аналіз температури повітря, а також рівня вологості і забруднення повітря. Розроблено математичну модель регулювання температури повітря у приміщенні, яка базується на визначенні ключових параметрів термодинамічної системи (теплове навантаження, потужність, що споживається і коефіцієнт корисної дії) відповідно ідеального циклу Карно. На основі розробленої моделі задачу оптимізації систем опалення, вентиляція та кондиціювання повітря було зведено до математичної задачі пошуку максимуму цільової функції сумарного значення коефіцієнту корисної дії. Вказано на базові підходи по модифікації і адаптації запропонованого підходу при вирішенні актуальних задач.

\footnotetext{
Список бібліографічного опису.

1. Маляренко В.А., Андрєєв С.Ю., Казарова І.О. (2018) Можливості підвищення комунальної енергетики втіленням когенерації. Міжнародний журнал «Світлотехніка та електроенергетика». Харків: ХНУМГ. №2(52). С. 59-62.

2. Казарова I.O. Підвищення ефективності систем енергопостачання за рахунок впровадження когенераиї: автореф. дис. на здобуття наук. ступеня канд. техн. наук, спец. 05.14 .06 "Технічна теплофізика та промислова теплоенергетика" / І.О. Казарова. - Харків, 2018. $-24 \mathrm{c}$.

3. Андрєєв С.Ю.,Маляренко В.А.,Шубенко О.Л.,Бабак М.Ю.,СенецькийО.В.,

Темнохуд І.О.,Казарова I.О. (2016)Когенерація водогрійних котельнях з котлами ПТВМ-100 при використанні органічного циклу Ренкіна. Інтегровані технології та енергозбереження. Харків: НТУ «ХПI», 2016. № 2. С. 48-60. ISSN 2078-5364.

4. Маляренко В.А., Казарова I.О., Сенецький О.В., Темнохуд О.О. (2019)Дослідження впровадження газопоршневих та газотурбінних двигунів при переведенні котельні в режим когенерації. Інтегровані технології та енергозбереження. НТУ «ХПИ»: сб. наук. пр. Харків: НТУ «ХПІ», № 2,с. 3-10.
} 


\section{References.}

1. Yoon, S., Yu, Y., Wang, J., \& Wang, P. (2018). Impacts of HVACR temperature sensor offsets on building energy performance and occupant thermal comfort. Building Simulation, 12(2), 259-271. doi: 10.1007/s12273-018-0475-3.

2. Abramski, M., Friedrich, T., Kurz, W., \& Schnell, J. (2011). Innovative Shear Connectors for a New Prestressed Composite Slab System for Buildings with Multiple HVACR Installations. Composite Construction in Steel and Concrete VI.doi: 10.1061/41142(396)9.

3. Sezdi, M., \&Uzcan, Y. (2016). Clean room classification in the operating room. 2016 Medical Technologies National Congress (TIPTEKNO).doi: 10.1109/tiptekno.2016.7863107.

4. Varghese, A. C., \& Palmer, G. (2016). Chapter 23 Clean room technology for low resource IVF units. Clean Room Technology in ART Clinics, 345-352. doi: 10.1201/9781315372464-24.

5. Silberstein, E. (2012). Residential construction academy: HVAC. Clifton Park, NY: Cengage Learning.

6. Muthuraman, S. (2016). Careers in HVACR: heating, ventilation, air conditioning, refrigeration. Chicago: Institute for Career Research.

7. Schijndel, A. W. M. V., \& Schellen, H. L. (2006). Application of a Combined Indoor Climateand HVAC Model for the Indoor Climate Performance of a Museum / Anwendung eines Modells für die Kombination des Innen klimas mit dem Heizungs-, Belüftungs- und Temperatur kontrollsystem (HBT; HVAC) zur Simulation des Raumklimas in einem IV Iuseum. Restoration of Buildings and Monuments, 12(3). doi: 10.1515/rbm-2006-6052.

8. Wright, J., \& Zhang, Y. (2008). Evolutionary Synthesis of HVAC System Configurations: Experimental Results. $H V A C \& R$ Research, 14(1), 57-72. doi: 10.1080/10789669.2008.10390993.

9. Balasubramanian, K., \&Cellatoglu, A. (2010). Selected Home Automation and Home Security Realizations: An Improved Architecture. Smart Home Systems. doi: 10.5772/8408.

10. Domb, M. (2019). Smart Home Systems Based on Internet of Things. IoT and Smart Home Automation [Working Title]. doi: 10.5772/intechopen.84894.

11. Saito, N. (2015). The concept of an ecological smart home network. Ecological Design of Smart Home Networks, 3-16. doi: 10.1016/b978-1-78242-119-1.00001-1.

12. Li, Y. L., Zhao, C. L., Liu, Y. Y., Peng, Q., \& Li, C. J. (2014). The Research of the Power Capsule Fan Energy Consumption in Thermal Balance Test Method. Applied Mechanics and Materials, 490-491, 902-909. doi: 10.4028/www.scientific.net/amm.490-491.902.

13. Abad, J. M. N., \& Soleimani, A. (2016). A neuro-fuzzy fan speed controller for dynamic management of processor fan power consumption. 2016 1st Conference on Swarm Intelligence and Evolutionary Computation (CSIEC).doi: $10.1109 /$ csiec.2016.7482121.

14. Simic, D., Kral, C., \& Pirker, F. (2005). Simulation of the cooling circuit with an electrically operated water pump. 2005 IEEE Vehicle Power and Propulsion Conference. doi: 10.1109/vppc.2005.1554567.

15. Liu, X., Jiang, Y., \& Zhang, T. (2016). Temperature and Humidity Independent Control (Thic) of Air-conditioning System. Berlin: Springer Berlin.

16. Quan, H. T. (2014). Maximum efficiency of ideal heat engines based on a small system: Correction to the Carnot efficiency at the nanoscale. PhysicalReviewE, 89(6). doi: 10.1103/physreve.89.062134.

17. Feidt, M. (2017). From Carnot Cycle to Carnot Heat Engine: A Case Study. Finite Physical Dimensions Optimal Thermodynamics 1, 75-97. doi: 10.1016/b978-1-78548-232-8.50003-0. 